\title{
Review of Feeding Techniques for Microstrip Patch Antenna
}

\author{
Abdullahi SB Mohammed \\ Department of Electrical and \\ Electronics Engineering, Kebbi \\ state University of Science and \\ Technology Aliero 1144, Nigeria
}

\author{
Aliyu Rufai Yauri \\ Department of ICT, Kebbi state \\ University of Science and \\ Technology Aliero 1144, Nigeria
}

\author{
A. M. Kabir \\ Department of Electrical and \\ Electronics Engineering, Kebbi \\ state University of Science and \\ Technology Aliero 1144, Nigeria
}

\begin{abstract}
This work analyzes the performance of different feeding techniques used in wireless communications applications for rectangular microstrip patch antennas, as in technologies such as Wimax, LTE and 5G application. Here are discussed various types of feeding arrangements. The performance of the microstrip patch antenna system depends on the antenna element and substrate characteristics as well as the feed configuration used.
\end{abstract}

\section{Keywords}

Fractal, Slot, Dielectric, DGS, Microstrip, Air-gap, Shorting pin

\section{INTRODUCTION}

The feedline is used to excite the antenna via direct or indirect radiation contact. Microstrip patch antennas can be supplied by a wide range of methods. These methods can be classified into two categories-contacting and non-contacting. In the contact method, the RF power is directly fed to the radiating patch using a connecting element, such as a microstrip line, coaxial probe and inset fed or notch fed while in the non-contacting fed, such as aperture coupling and proximity coupling, electromagnetic field coupling is done to transfer power between the microstrip. The selection of feeding technique for a microstrip patch antenna is an important decision because it directly affects the bandwidth, returns loss and performance of antenna efficiency [1]. If the thickness of the substrate is increased then surface waves and spurious feed radiation also increases, which directly hampers the bandwidth of the antenna [2]. The popularly used contacting feed methods are microstrip feed and co-axial feed. On the other hand, in non-contacting feed method, the patch of the antenna is indirectly fed with the RF power and the RF power is transported to the patch through an electromagnetic coupling. The most commonly used noncontacting feeding techniques are aperture coupled feed and proximity coupled feed [3-5]. These popular feeding methods are discussed briefly as follows.

\section{MICROSTRIP FEED}

In this type of feeding method shown in Figure 1. A conducting strip is linked directly to the boundary of the microstrip patch. This feed arrangement has a key advantage that the feed and patch can be grafted on the same substrate, making it a flat structure [6-7].

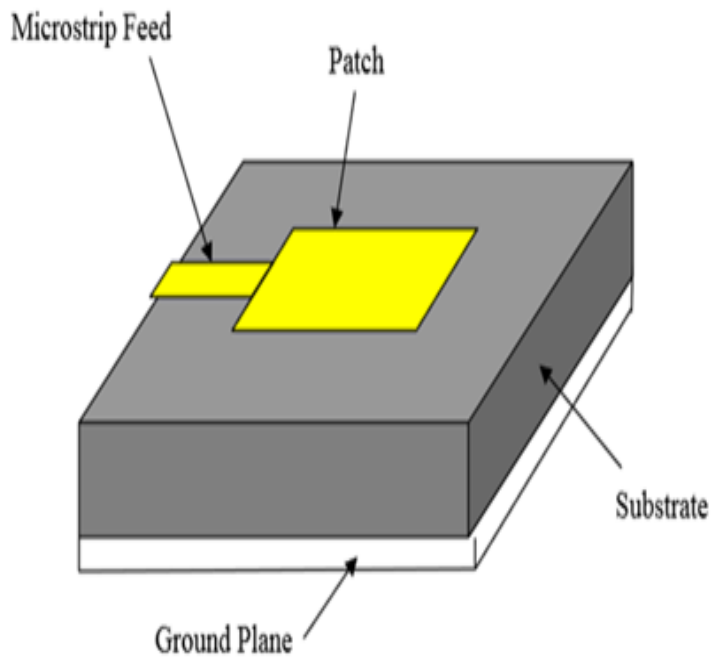

Figure 1. Microstrip fed patch antenna [7]

\section{a. Coaxial Feed}

The coaxial feed shown in Figure 2. Also called probe feed is broadly used technique for feeding microstrip patch antennas. In this technique, the inner conductor of the coaxial connector is drawn through the dielectric and soldered on the radiating patch, while the outer conductor is attached to the ground plane [8].

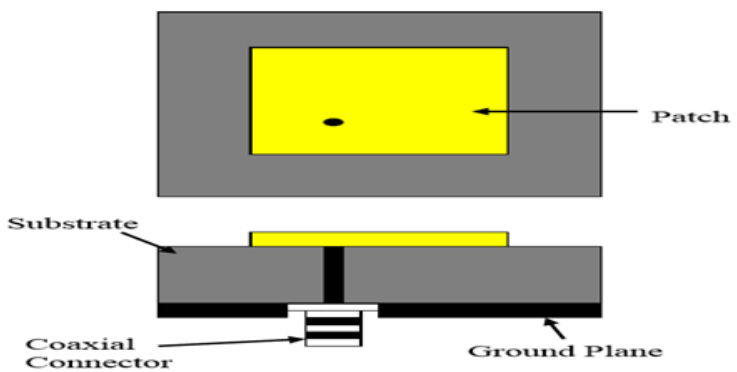

Figure 2. Coaxial fed patch antenna [8]

\section{b. Aperture Coupled Feed}

In opening coupling feed and ground plane with aperture in Figure 3 [9]. Two different substrates are sandwiched to provide electromagnetic coupling from feed to the radiating patch structure. The radiating patch element is grafted to the top of the antenna substrate and the microstrip feed line is grafted onto the bottom of the feed substratum to achieve aperture coupling. The thickness and dielectric constants of these two substrates would be chosen separately to optimize the different electrical functions of radiation and circuitry. The coupling aperture is preferably placed in the center of the patch, which 
results in less cross-polarization due to the symmetricity of the configuration [9].

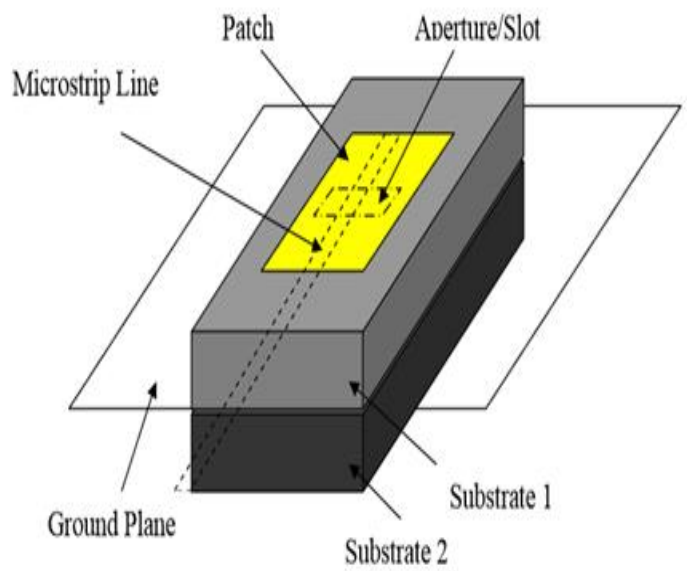

Figure 3. Aperture coupled fed patch [9]

\section{c. Proximity Coupled Feed}

Two dielectric substrates are used in this technique to place the feed line between the two substrates and the radiating patch is located on top of the upper substrate as shown in Figure 4 [10]. The main benefit of this feeding technique is that it eliminates spurious feed radiation and offers very high bandwidth. This scheme also provides an alternative between two different dielectric media, one for the patch and the other for the feed line. The main drawback of this feeding scheme is that it is complex to manufacture because both dielectric layers need to be properly aligned [10].

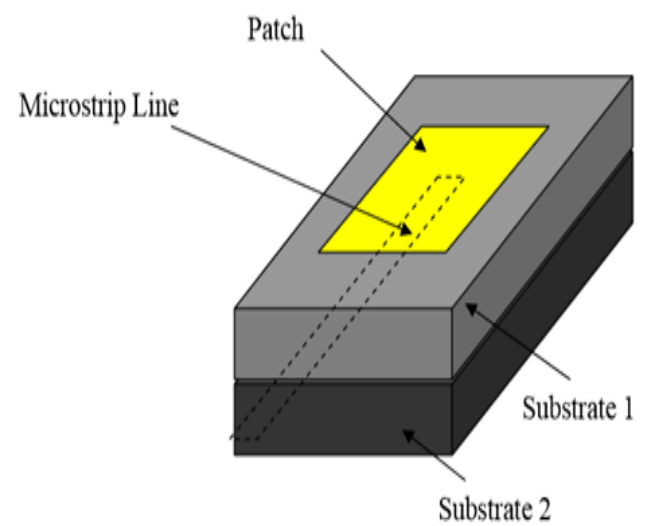

Figure 4. Proximity fed patch antenna [10]

In addition to the various feeding techniques mentioned above, several other methods have been adopted in recent times to improvise the inherent issue of gain and bandwidth in highfrequency microstrip antennas. A brief insight into such popular methods is outlined below; parasite patch; air gap; dual feed slots; a dielectric substrate; shortening pin and defective ground structures. These feeding methods are discussed briefly as follows:

\section{d. Parasitic Patch}

Parasitic patch technique is used to improve bandwidth and gain antennas for microstrip patch. There are two different configurations in the parasitic patch: one is coplanar and the other is stacked technique as shown in Figure 5 [11]. In coplanar technology, different patches are incorporated above the dielectric substrate on a single plane. An excitation is given between different patch radiators, which is called the main patch. In stacked technology, a patch is used over another patch with an intermediate dielectric layer. This allows two or more patches to divide the common opening area [12-14]. Parasitic patch with a lower dielectric constant are usually added above the radiating patch in the stacked antenna configuration. This minimizes the effectiveness of the multilayer antenna overall and increases the antenna gain [15]. Multi-layered microstrip antennas can maintain size and reduce surface wave effect [11].

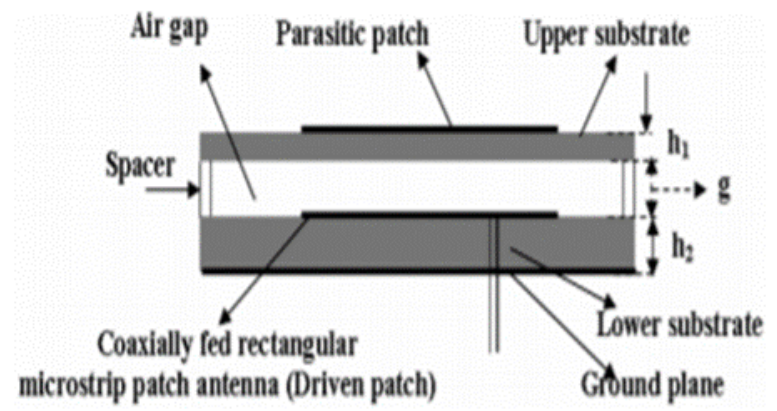

Figure 5. Stacked patch antenna with parasitic element [11]

\section{e. Air Gap}

The air as a dielectric has a lower permittivity, so it gives an effective radiation pattern and low return loss when used as a dielectric substrate between the reflecting and the radiating patch as in Figure 6 [16]. These results indicate that the maximum power input is converted to electromagnetic waves. It is observed that placing an air gap between the single patch antenna and the coupling aperture helps to resonate on two different frequencies. In addition, the ratio of two different resonating frequencies decreases with increasing the height of the air gap and they are closer to each other [16]. This shows that the air gap improves the bandwidth of the microstrip patch antenna.

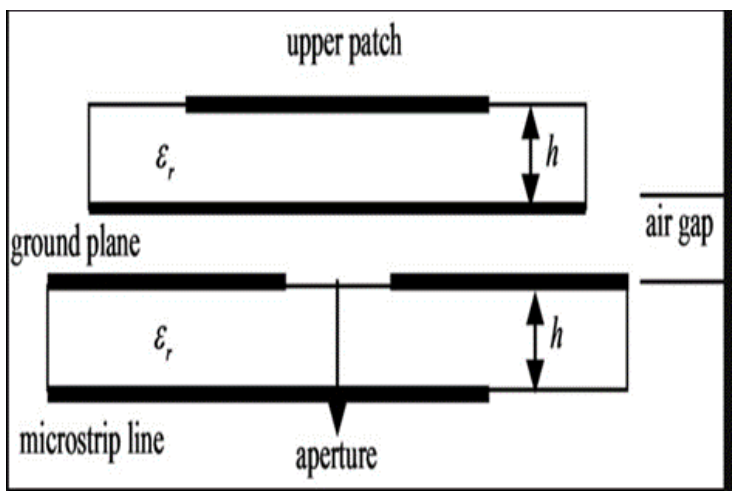

Figure 6. Microstrip patch antenna with air gap [16]

\section{f. Patch antenna with Slits and Slots}

With the help of slot size of microstrip patch antenna is reduced as shown in Figure 7 [17]. This effect can be done by changing the path of current. When slots are cut into patch, current is changed. The patched antennas with slots and slits is to achieve patch size reduction [17]. Adding slots to the antenna patch adds a new frequency of resonance. By adding more slots, two or more resonance regions are created, resulting in increased bandwidth after proper optimization. [18-21]. 


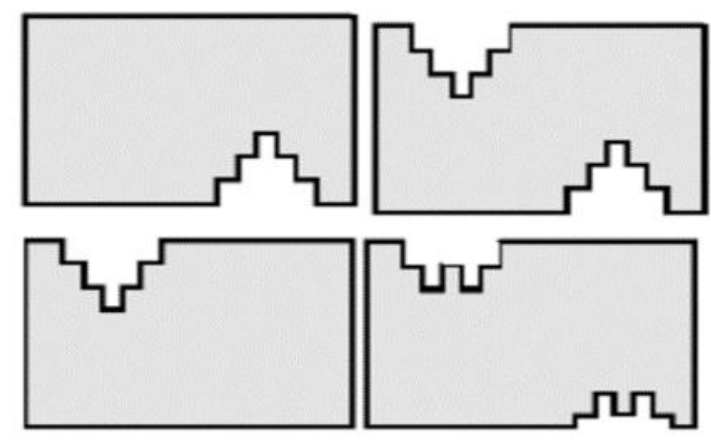

Figure 7. Slots with irregular shapes [17]

\section{g. Dual Feed}

The dual feed is another technique available to improve bandwidth, particularly at higher resonant frequencies [22]. Double antenna feeding configuration is used to enforce vertical current mode. It also prevents other modes, such as horizontal and asymmetric current modes, from being excited. These horizontal and asymmetrical current modes degrade the polarization properties and reduce the impedance and performance of the antenna. Figure 8 shows a dual-band 5G antenna which has sector-disk radiating patch is placed non concentrically inside a circular-shaped slot matched off the ground plane [represents a ground plane aperture (GPA)]. The center of the circular GPA is on the same vertical symmetric line of the substrate. The patch is excited using a 50- $\Omega$ proximity-feed microstrip line placed on the other side of the substrate. The feed line is tapered to use as transformer to improve the impedance matching.

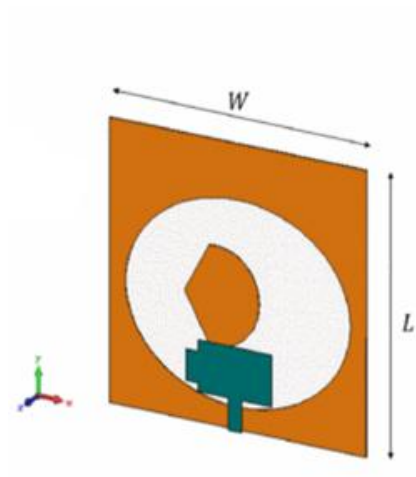

(a)

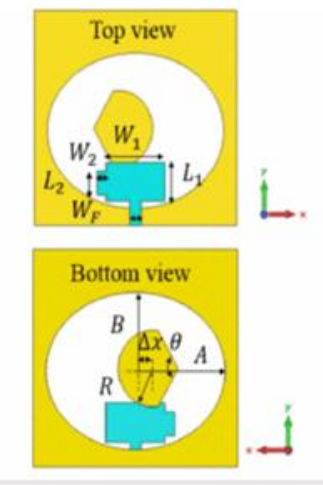

(b)
Figure 8. An example of dual-band 5G antenna, (a) 3D view and (b) Top and bottom views from [22]

\section{h. Dielectric Substrate}

The selection of suitable substrates is an important task in the design of the microstrip patch antenna. Some critical parameters such as bandwidth, efficiency and radiation pattern of the patch antenna are improved by selecting the appropriate dielectric material for the substrate [23]. The substrates are mainly used for the mechanical strength of the antenna in the microstrip antenna. In addition, by selecting appropriate dielectric mediums, it can also reduce the spread of the surface wave. Surface waves extract part of the total power available for radiation, which degrades the electrical properties of the antenna [24- 26].

\section{i. Shorting Pin}

Adding a short pin to the patch antenna reduces the resonating frequency of the antenna without reducing the size of the antenna [27]. To achieve a high impedance match, the location of the shorting pin must be selected closer to the antenna feed point as shown in Figure 9. If not, the impedance of input increases rapidly. The short pin may also act as the microstrip antenna feed line. The short pin is modeled as an inductive partial parallel to the LC circuit of the resonator. The resulting resonance frequency will be larger the inductive part.

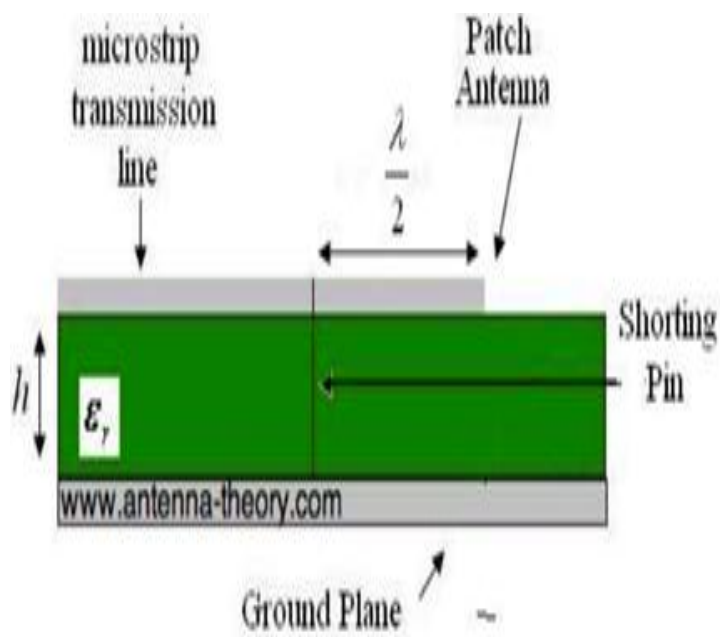

Figure 9. Half-wavelength patch with shorting pin at the feed [27]

That ultimately increases the degree of miniaturization for a fixed operating frequency. The shorting pin not only increases the performance of the bandwidth but also reduces crosspolarization. The cross-polarized level in the $\mathrm{H}$ plane can be cancelled by using shortened anti-phase pins [28].

\section{j. Defective Ground Structures}

Defected ground structures have recently been developed and are achieved by graving a simple defect of any shape on the ground plane. Due to these structures, the current in the ground plane is disturbed as shown in Figure 10. This ultimately leads to the excitation and spread of radio waves throughout the substrate layer. DGS configuration also helps to change the transmission capacity and inductance parameters of the viz line [29]. To achieve the desired performance, the ground defect can be changed from simple to complex. Default microstrip ground structures have many advantages in the field of transmission lines, couplers, dividers, power amplifiers and oscillators [3031]. Popular feeding techniques for giving the excitation signal to microstrip patch antennas are summarized in Table 1 .

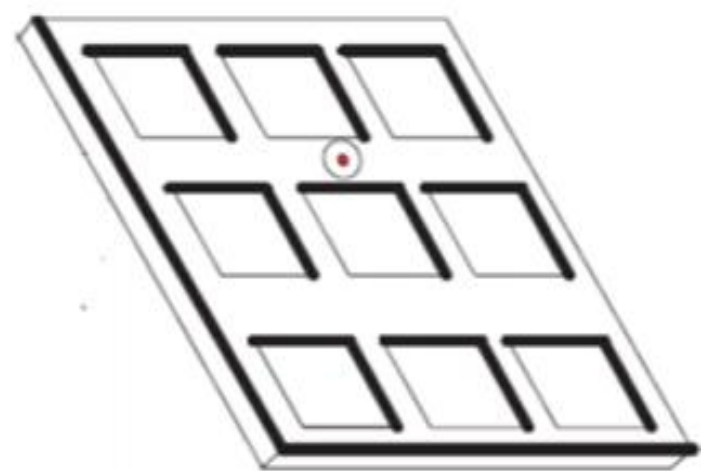

Figure 10. Front and back view of defective ground plane [29] 
Table 1. Comparing the Different Feed Techniques.

\begin{tabular}{|c|c|c|c|}
\hline $\begin{array}{l}\text { S/ } \\
\text { n } \\
\text { o }\end{array}$ & $\begin{array}{l}\text { Tech } \\
\text { nique } \\
\mathbf{S}\end{array}$ & Characteristic & $\begin{array}{l}\text { Refer } \\
\text { ence }\end{array}$ \\
\hline $\mathrm{a}$ & $\begin{array}{l}\text { Micro } \\
\text { strip } \\
\text { Line }\end{array}$ & $\begin{array}{c}\text { More spurious fed radiation, Easy } \\
\text { Impedance matching and fabrication, } \\
\text { bandwidth achieved is } 2-5 \% \text { and it also } \\
\text { more reliable. }\end{array}$ & [6] \\
\hline $\mathrm{b}$ & $\begin{array}{l}\text { Coaxi } \\
\text { al } \\
\text { Feed }\end{array}$ & $\begin{array}{l}\text { More spurious fed radiation, Easy } \\
\text { Impedance matching, fabrication needed } \\
\text { soldering and drilling, bandwidth } \\
\text { achieved is } 2-5 \% \text { and reliability is poor } \\
\text { due to soldering. }\end{array}$ & [8] \\
\hline $\mathrm{c}$ & $\begin{array}{l}\text { Apert } \\
\text { ure } \\
\text { Coupl } \\
\text { e } \\
\text { Feed }\end{array}$ & $\begin{array}{l}\text { Less spurious fed radiation, Easy } \\
\text { Impedance matching, fabrication needed } \\
\text { alignment ,bandwidth achieved is } 2-5 \% \\
\text { and reliability is good. }\end{array}$ & [9] \\
\hline $\mathrm{d}$ & $\begin{array}{l}\text { Proxi } \\
\text { mity } \\
\text { Coupl } \\
\text { e } \\
\text { Feed }\end{array}$ & $\begin{array}{l}\text { Minimum spurious fed radiation, Easy } \\
\text { Impedance matching, fabrication needed } \\
\text { alignment, bandwidth achieved is } 13 \% \text { and } \\
\text { reliability is good. }\end{array}$ & [10] \\
\hline $\mathrm{e}$ & $\begin{array}{l}\text { Parasi } \\
\text { tic } \\
\text { Patch }\end{array}$ & $\begin{array}{l}\text { Used to improve the impedance matching } \\
\text { of the antenna, thereby resulting in } \\
\text { multiband and broadband performances. } \\
\text { used in antennas to change the radiating } \\
\text { field patterns, and steer the beam. }\end{array}$ & [11] \\
\hline$f$ & $\begin{array}{l}\text { Air- } \\
\text { gap }\end{array}$ & $\begin{array}{l}\text { Helps to reduce the spread of surface wave } \\
\text { effects on the antenna. }\end{array}$ & {$[16]$} \\
\hline $\mathrm{g}$ & $\begin{array}{l}\text { Patch } \\
\text { es } \\
\text { with } \\
\text { Slits } \\
\text { and } \\
\text { Slots }\end{array}$ & $\begin{array}{l}\text { Helps to change the resonant frequency } \\
\text { bands, increase the electrical length of the } \\
\text { radiating patch. }\end{array}$ & [17] \\
\hline $\mathrm{h}$ & $\begin{array}{l}\text { Dual } \\
\text { Feed }\end{array}$ & $\begin{array}{l}\text { Are commonly used to change the } \\
\text { antenna's reactive impedance. }\end{array}$ & [22] \\
\hline i & $\begin{array}{l}\text { Perfe } \\
\text { ct } \\
\text { Diele } \\
\text { ctric } \\
\text { Subst } \\
\text { rate }\end{array}$ & $\begin{array}{l}\text { Helps to reduce the spread of surface wave } \\
\text { effects on the antenna, it allows } \\
\text { miniaturization of the antenna model }\end{array}$ & [23] \\
\hline $\mathrm{j}$ & $\begin{array}{l}\text { Shorti } \\
\text { ng } \\
\text { Pin }\end{array}$ & $\begin{array}{l}\text { Helps to reduce the size of the model, } \\
\text { provide multiple paths to currents and } \\
\text { allow the antenna to radiate at multiple } \\
\text { frequencies and add stability to the } \\
\text { antenna model by allowing it to maintain } \\
\text { its performance in adverse situation. }\end{array}$ & [27] \\
\hline $\mathrm{k}$ & $\begin{array}{l}\text { Defec } \\
\text { tive } \\
\text { Grou } \\
\text { nd } \\
\text { Struct } \\
\text { ure }\end{array}$ & $\begin{array}{c}\text { Improve the gain and bandwidth of the } \\
\text { antenna without increasing its height and } \\
\text { volume. }\end{array}$ & [29] \\
\hline
\end{tabular}

\section{CONCLUSION}

The intent of this paper has been to provide a summary of feeding techniques, in order to highlight the high degree of flexibility and versatility that microstrip patch antenna can off er. A comprehensive survey on various feeding techniques for the design of microstrip patch antenna has been done through this paper. From the inferences of the feeding techniques literature survey, it is observed that slits can be used for multiband performance, slots can be used for determining the frequency, a thick dielectric material such as that stacking method increases gain and impedance bandwidth. Increase in microstrip ground size increases antenna gain. All having low dielectric constant yields large bandwidth. The effect of integrating those modern techniques like a slit, slotted patch, usage of thick dielectric material, meander line, hexagonal, shaped patch, fractal structure, and stacking, provide a small profile, multiband, large gain and a compact antenna element

\section{ACKNOWLEDGMENT}

This work was supported by Tetfund (TETF/ES/UNIV/KEBBI/ASTD/2008)

\section{REFERENCES}

[1] Suhana Rashid, Chandan Kumar Chakrabarty, Bandwidth Enhanced Rectangular Patch Antenna Using Partial Ground Plane Method for WLAN Applications.: Universiti Tenaga Nasional, Putrajaya Campus. 2015. The 3rd National Graduate Conference.

[2] Garg, R., Bhartia, P., Bahl, I., Ittipiboon, “A., Microstrip Antenna Design Handbook”, Artech House, Inc, 2001.

[3] Yang F., X. Zhang, X. Ye, and Y. Rahmat-Samii, Wideband E-shaped patch antennas for wireless communications", IEEE Transactions on Antennas and Propagation, Vol. 49, No. 7, pp. 1094-1100, Jul. 2001.

[4] Ge, Y., K. Esselle, and T. Bird, "E-shaped patch antennas for high speed wireless networks", IEEE Transactions on Antennas and Propagation, Vol. 52, No. 12, pp. 32133219, Dec. 2004.

[5] S K Behera, "Novel Tuned Rectangular Patch Antenna as a Load for Phase Power Combining" PhD Thesis, Jadavpur University, Kolkata, 2012.

[6] Gurdeep Singh, Jaget Singh, "Comparative Analysis of Microstrip Patch Antenna with Different Feeding Techniques", International Conference on Recent Advances and Future Trends in Information Technology, Proceedings published in International Journal of Computer Applications ${ }^{\circledR}$ (IJCA), 2012.

[7] Dipak K. Neog, Shyam S. Pattnaik, Dhruba. C. Panda, Swapna Devi, BonomaliKhuntia, and Malaya Dutta, Design of a Wideband Microstrip Antenna and the Use of Artificial Neural Networks in Parameter Calculation", IEEE Antennas and Propagation Magazine, Vol. 47, No.3, June 2005 .

[8] Gurdeep Singh, Jaget Singh, "Comparative Analysis of Microstrip Patch Antenna with Different Feeding Techniques", International Conference on Recent Advances and Future Trends in Information Technology, pp. 18-22, 2012.

[9] Fong, F.S., H.F. Pues and M.J. wither, "wideband multilayer coaxial-feed Microstrip antenna element". Electronics letters, vol 21, pp. 497-498, 1985. 
[10] Yoshita Gupta, "Stacked Microstrip Patch Antenna with Defected Ground Structures for W-lan and Wimax Applications" Thesis work in Department of Electronics and Communication Engineering, THAPAR UNIVERSITY, PATIALA, June, 2014

[11] J. Anguera, G. Font, C. Puente, C. Borja, and J. Soler, "Multifrequency microstrip patch antenna using multiple stacked elements," IEEE Microwave and Wireless Components Lett., vol. 13, no. 3, 13(3), pp. 123-124, March 2003

[12] Pozar, D.M. and B. Kaufman, "Increasing the bandwidth of a Microstrip antenna by proximity coupling", Electronics letters, vol 23, no. 8, pp. 368-369, April 1987

[13] Gurdeep Singh, Jaget Singh, "Comparative Analysis of Microstrip Patch Antenna with Different Feeding Techniques", International Conference on Recent Advances and Future Trends in Information Technology, pp. 18-22, 2012.

[14] Hao Jiang, Zhenghui Xue, Weiming Li and Wu Ren, "Broad beamwidth stacked patch antenna with wide circularly polarized bandwidth", Electronics Letters, Vol. 51, No. 1, pp. 10-12, 8th January 2015.

[15] Dong, J., Wang, A., Wang, P., \& Hou, Y. (2008, November). A novel stacked wideband microstrip patch antenna with U-shaped parasitic elements. In Antennas, Propagation and EM Theory, 2008. ISAPE 2008. 8th International Symposium on (pp. 185-188). IEEE.

[16] Dahele, J. S., and Kai F. Lee. "Theory and Experiment on Microstrip Antennas with Airgaps." IEEE Proceedings on Microwaves, Antennas and Propagation, Vol. 132, No. 7, 1985.

[17] Chakraborty, Shatabdi, and Shweta Srivastava, "High Gain Annular Ring Antenna", International Conference on Devices and communications (ICDeCom), 2011.

[18] Chen, D. and C. H. Cheng, "A novel compact ultrawideband (UWB) wide slot antenna with via holes" Progress in Electromagnetics Research, Vol. 94, pp. 343349,2009

[19] Hatem H. Abbas, Jabir S. Aziz, "Bandwidth enhancement of Microstrip patch antenna", Journal of mobile communication, vol. 4, pp. 54-59, 2010.

[20] Yoon, N., \& Seo, C. (2017). A 28-GHz wideband $2 \times 2$ Uslot patch array antenna. Journal of Electromagnetic Engineering and Science, 17(3), 133-137.

[21] Neha Kothari \& Sunil Sharma; A 28-GHz U-slot Microstrip Patch Antenna for 5G Applications,
International Journal of Engineering Development and Research (www.ijedr.org) 2018 IJEDR | Volume 6, Issue 1 | ISSN: 2321-9939.

[22] Waterhouse, R. B., \& Shuley, N. V. (1992). Dual frequency microstrip rectangular patches. Electronics Letters, 28(7), 606-607.

[23] Deng, S. M. (2001). U.S. Patent No. 6,211,825 Washington, DC: U.S. Patent and Trademark Office. White, C. R., \& Rebeiz, G. M. (2010)

[24] A differential dual-polarized cavity-backed microstrip patch antenna with independent frequency tuning. IEEE Transactions on Antennas and Propagation, 58(11), 34903498.

[25] Antonino-Daviu, M. Cabedo-Fabres, M. Ferrando Bataller, A Valero-Nogueira, "Wideband Doubke fed Planar monopole antenna", Institution of engineering and Technology, vol. 39,200.

[26] H. Grannum, R. D. Errico, C. Roblin, A. Sibille, "Small semi directional antenna for UWB terminal Application", First European Conference on Antenna and Propagation, pp.1-6, 2006

[27] Ansari, J. A., Singh, P., Yadav, N. P., \& Vishvakarma, B. R. (2009). Analysis of shorting pin loaded half disk patch antenna for wideband operation. Progress in Electromagnetics Research, 6, 179-192.

[28] Malekpoor, H.; Jam, S., "Enhanced Bandwidth of Shorted Patch Antennas Using Folded-Patch Techniques," Antennas and Wireless Propagation Letters, IEEE, vol.12, pp.198-201, 2013.

[29] Mustapha, L., \& Jecko, B. (2008). EBG structure with wide defect band for broadband cavity antenna applications. IEEE Antennas and Wireless Propagation Letters, 7, 693-696.

[30] Geng, J. P., Li, J., Jin, R. H., Ye, S., Liang, X., \& Li, M. (2009). The development of curved microstrip antenna with defected ground structure. Progress In Electromagnetics Research, 98, 53-73.

[31] Khan, M. T., Zakariya, M. A., Saad, M. N. M., Baharudin, Z., \& Rehman, M. U. (2013, December). Parametric effect of defected ground structure (DGS) on frequency of a bandpass filter. In RF and Microwave Conference (RFM), 2013 IEEE International (pp. 184-188). IEEE.

[32] Sung, Y. J., Kim, M., \& Kim, Y. S. (2003). Harmonics reduction with defected ground structure for a microstrip patch antenna. IEEE antennas and wireless propagation Letters, 2, 111-113. 